\title{
Parkinsonism Due to Mutations in PINK1, Parkin, and DJ-1 and Oxidative Stress and Mitochondrial Pathways
}

\author{
Mark R. Cookson \\ Laboratory of Neurogenetics, National Institute on Aging, National Institutes of Health, Bethesda, \\ Maryland 20892 \\ Correspondence: cookson@mail.nih.gov
}

\begin{abstract}
Three genes have been identified that cause, in humans, autosomally inherited parkinsonism. These are PARK2, encoding the E3 ubiquitin ligase parkin; PINK1, a mitochondrial kinase; and $P A R K 7$, which codes for the protein DJ-1. In several experimental systems, it has been shown that all three proteins impact mitochondrial function and/or oxidative stress responses. These are probably related because mitochondria produce oxidative stress in neurons. Moreover, it is clear that there are relationships between these genes, with a single pathway linking PINK1 and parkin and a parallel relationship with DJ-1. Work in progress in the field is aimed at understanding these relationships in more depth.
\end{abstract}

$\mathrm{O}$ ne of the promises of the genetic discoveries in Parkinson's disease (PD) is that the genes will give insight into etiology. One aspect of this is that understanding the biological processes that go awry when genes are mutated will lead to insights regarding dopamine neuron survival. In the longer term, it is further hoped that some of these pathways might be tractable for new therapeutic approaches.

However, genes and their protein products do not work alone in the cell but are, rather, organized into pathways. Proteins can have multiple functions within cells, some of which may be dependent on the signaling context of the pathway. Hence, although considering individual genes is important, we might also want to understand their relationships because this might yield important clues as to which functions are important in a specific phenotype.

The data discussed here center on three genes associated with familial parkinonsonism: parkin, PINK1 (PTEN-induced novel kinase 1 ), and DJ-1. I cover the data that support the notion that all of the protein products of these genes have functions related to the maintenance of mitochondria, particularly under conditions of cellular stress. I also discuss what is known regarding the relative relationships of these three genes and show that, although sometimes there are straightforward genetic pathways, there may also be more complex arrangements. First, it is important to understand the phenotype associated with these mutations in humans.

Editor: Serge Przedborski

Additional Perspectives on Parkinson's Disease available at www.perspectivesinmedicine.org

Copyright (C) 2012 Cold Spring Harbor Laboratory Press; all rights reserved; doi: 10.1101/cshperspect.a009415

Cite this article as Cold Spring Harb Perspect Med 2012;2:a009415 
M.R. Cookson

\section{PARKIN, PINK1, AND DJ-1 MUTATIONS CAUSE PARKINSONISM, NOT PARKINSON'S DISEASE}

In the original descriptions of patients with autosomal juvenile recessive parkinsonism (ARJP), the point was made emphatically that ARJP differed from other types of parkinsonism (Ishikawa and Tsuji 1996). Although the clinical signs of parkinsonism are present by definition, the course of the disease starts early and is generally mild and responsive to low-dose L-dopa treatment throughout the duration of the disease. In the early cases, marked sleep benefit and dystonia were also noted.

The pathology of ARJP also differs from other forms of parkinsonism. Specifically, although there is loss of dopaminergic neurons in the substantia nigra pars compacta, Lewy bodies characteristic of sporadic Parkinson's disease were not reported in the early cases (Yokochi 1997). Subsequently, there have been reports of $\alpha$-synuclein inclusions in authentic ARJP cases (Sasaki et al. 2004), but these structures are outside of the substantia nigra and appear morphologically distinct from classic brainstem Lewy bodies.

The underlying mutations in these ARJP cases were mapped to a gene on chromosome 6, PARK2, that encodes for a protein designated "parkin" in the original paper (Kitada et al. 1998). Early reports included several deletions of multiple exons of PARK2, and subsequent surveys have shown that there are a very large number of deletions, duplications, nonsense, and truncated mutations in the same gene. Overall, $P A R K 2 /$ parkin mutations account for about half of known cases of autosomal-recessive parkinsonism (Nuytemans et al. 2010). Because of the nature of mutations, including mutations that will very likely disrupt function, and the autosomal-recessive inheritance of ARJP, the human genetic data suggest that parkin mutations cause disease through a loss of function.

After the cloning of parkin, two more genes for autosomal-recessive parkinsonism were cloned, both mapping to chromosome 1. DJ-1 (Bonifati et al. 2003) had been cloned previously as an oxidative stress response protein, whereas
PINK1 (Valente et al. 2004) had been identified in a microarray screen and named as "PTENinduced novel kinase 1.” PINK1 mutations are less frequent than parkin mutations, and DJ-1 mutations are quite rare, but both genes are probably loss-of-function mutations given the presence of frameshift, early termination, and deletion mutations (Nuytemans et al. 2010).

Critical for this discussion, both PINK1 and DJ-1 cause autosomal-recessive parkinsonism clinically and thus resemble the phenotype of $P A R K 2 /$ parkin mutations with early onset and a prolonged clinical course. The neuropathology of PINK1 and DJ-1 cases is not well established. One convincing mutation in PINK1 has come to autopsy and did have Lewy bodies, although there was an unusual clinical history including polysubstance abuse (Samaranch et al. 2010). No reports of DJ-1 pathology are available in the literature at this time.

Overall, the picture of all three of these mutations is that they all share parkinsonism as a major clinical feature but that the phenotype is not the same as sporadic Lewy body PD. This could be a point of semantics, but it might be important in understanding how far we can extrapolate from one set of disease to another. Because there are many causes of parkinsonism, there is no a priori reason to link all genes together. Instead, it has been argued that saying that all PARK loci cause the same disease inappropriately conflates disparate causes into a single pathway (Hardy and Lees 2005; Hardy et al. 2009; Klein et al. 2009).

Therefore, despite the clinical similarity of PINK1, parkin, and DJ-1 cases and in the absence of firm pathological data, what evidence is there to argue for or against these genes functioning together in a single pathway? Much of the data addressing whether there are specific pathways for these three proteins derive from organisms other than humans, thus it is important to understand how well conserved the proteins are.

\section{EVOLUTION OF DJ-1, PINK1, AND PARKIN}

DJ-1 is an evolutionarily ancient protein, because clear homologs can be found in all aerobic species as diverse as Escherichia coli and human 
PINK1, Parkin, and DJ-1

(Bandyopadhyay and Cookson 2004; Lucas and Marin 2007). In some species, such as Drosophila melanogaster or Caenorhabditis elegans, there are two paralogs with different tissue expression patterns. For example, one of the fly homologs, DJ- $1 \alpha$, is restricted to the male germline, whereas the other, DJ-1 $\beta$, is expressed in most tissues (Meulener et al. 2005). Although the precise biochemical function is not known, it has been proposed that DJ-1 may play a role in cellular responses to oxidative stress. If dopamine neurons are lost in parkinsonism, then it follows that one way in which dopamine neurons might be lost is by exposure to oxidative stress, a theory for which there was a good amount of support before the cloning of DJ-1 (Surmeier et al. 2011).

Both parkin and PINK1 are also conserved proteins to some extent but not quite to the same level as DJ-1, because homologs are found in most known animal species, including flies, worms, and mice, but not in bacteria or plants. Both are also members of much larger gene families; parkin is one of several hundred ubiquitin-protein E3 ligases, and PINK1 is predicted to be a serine/threonine protein kinase.

The specifics of the functions of these two enzymes are important to this discussion and are dealt with below, but one additional observation from the gene sequence is that PINK1 has an amino-terminal mitochondrial targeting sequence. Following the logic of DJ-1, if loss of PINK1 affects dopamine neurons, then this suggests that there are aspects of mitochondrial function important in parkinsonism, a hypothesis that again had been evaluated in the PD field for several years (Yao and Wood 2009).

If mitochondria are a nexus for parkinsonism associated with PINK1 mutations, then it might be logical that homologs are found in many organisms with mitochondria, that is, animals but not bacteria. But, because there are no clear PINK1 homologs in yeast, the function of this protein might be more recently acquired than the acquisition of mitochondria. Immediately, one might expect therefore that PINK1 function might not be essential for general mitochondrial function but, rather, for some more specialized function.
PINK1 and DJ-1 therefore made predictions regarding the types of cellular processes that might be important in recessive parkinsonism, namely, oxidative stress and mitochondria. Given that mitochondria are a major source of reactive oxygen species in mammalian cells, these might seem to be related to one another. However, parkin as an E3 ligase was not obviously related to either of these processes, and the likely role in protein degradation was emphasized in many articles.

Therefore, for one human condition, there are three genes that are conserved across evolution but, based on sequence data, are likely involved in different biological processes. Based on this, it is not clear if PINK1, parkin, and DJ-1 are in a single pathway or if they in effect phenocopy each other. Part of the answer to this question came from examining model systems of loss of function in other organisms, which, in turn, led to understanding that there were genetic pathways involved.

\section{PATHWAYS TO PARKINSONISM}

Given that mutations are loss of function, a reasonable way to try to model the disease should be to knock out PINK1, parkin, or DJ-1. For reasons that are not clear, this has not led to striking results in mice because even triple knockouts of all three genes did not have loss of dopaminergic neurons when aged to 2 yr old (Kitada et al. 2009).

But, in Drosophila models, knockout of parkin had dramatic effects. Although there are many E3 ligases, there appears to be one reasonably clear homolog of human parkin in flies. Genomic knockout of this homolog led to loss of flight muscles and male sterility. Interestingly, and surprisingly, these effects both appeared to be due to mitochondrial damage (Greene et al. 2003). Also striking was the report that Drosophila parkin mutants show increased sensitivity to oxidative stress (Pesah et al. 2004). Therefore, knockout of parkin in this simple organism seemed to link the two theories regarding loss of dopamine neurons discussed above, although the phenotypes were very striking and not simply loss of dopamine neurons; in fact, loss of 
neurons was not seen in one of the models ( $\mathrm{Pe}$ sah et al. 2004). Unbiased assays of the proteome also highlighted mitochondrial dysfunction in parkin knockout mice, although without such dramatic morphological effects as seen in flies (Palacino et al. 2004).

This story became even more interesting when PINK1-deficient flies were made. Two groups independently showed that Drosophila lacking the single PINK1 homolog had the same types of muscle degeneration, male infertility, and mitochondrial phenotypes as the parkin mutants (Clark et al. 2006; Park et al. 2006). These phenotypes were PINK1 dependent because the human homolog could rescue the PINK1-deficiency phenotypes, which also shows that the Drosophila and human genes were functionally conserved.

Furthermore, although overexpression of parkin could at least partially rescue PINK1 phenotypes, the reverse was not true, implying a genetic pathway in which PINK1 is upstream of parkin. This is an important result because it implies that the phenotypes seen in different gene mutations are not phenocopies but can be used to indicate something specific regarding gene relationships. Furthermore, this putative relationship between PINK1 and parkin seems to strengthen the concept that parkin has an effect in the control of mitochondrial function.

In contrast, the relationship between $D J-1$ and the other two genes discussed here is more complex. The original reports of DJ-1 knockout flies did not show such dramatic mitochondrial phenotypes, although they were reported to have altered sensitivity to oxidative stressors (Menzies et al. 2005; Meulener et al. 2005; Park et al. 2005; Yang et al. 2005; Lavara-Culebras and Paricio 2007). However, more recent examinations of aged flies have revealed mitochondrial defects and shown that increased expression of DJ-1 can complement loss of PINK1, but not parkin function (Hao et al. 2010). Overall, this suggests that DJ-1 acts in parallel, or perhaps downstream from PINK1, but is probably not a central part of the PINK1/parkin pathway.

Although these data were therefore incredibly important in developing ideas regarding relationships between different genes for parkin- sonism, they did not immediately provide a biochemical explanation for why these proteins might have a similar effect. Although this is an active area of research, there have been several developments that have begun to resolve this issue.

\section{BIOCHEMICAL FUNCTION IN THE PINK1/PARKIN PATHWAY}

One question that initially seemed obscure is why parkin would have mitochondrial effects. Specifically, most studies of wild-type or mutant parkin reported cytosolic and nuclear localization (Cookson et al. 2003; Sriram et al. 2005; Hampe et al. 2006), although some studies noted a small mitochondrial pool of the protein (Darios et al. 2003; Kuroda et al. 2006). Therefore, to have such strong mitochondrial effects, either parkin must be able to localize to mitochondria under some circumstances or must have an indirect effect on mitochondrial function via an undefined cytoplasmic or nuclear activity.

Support for the first possibility came from a series of experiments performed largely in HeLa cells in culture exposed to agents that depolarize mitochondria such as the protonophore CCCP (Narendra et al. 2008). In these experiments, parkin was normally found in the cytoplasm and nucleus as previously reported but under conditions in which mitochondrial membrane potential (MMP) was disrupted, parkin was rapidly relocalized to the depolarized organelles. After recruitment, parkin mediated the selective turnover of depolarized mitochondria via autophagy, a form of lysosomal clearance also known as mitophagy. The expression of parkin helps to clear mitochondria that have mutations in the mitochondrial DNA (mtDNA) (Suen et al. 2010), suggesting that it might be an important form of mitochondrial quality control.

These data were then extended mechanistically to reconcile this cellular effect of parkin with its known biochemical activity as an E3 protein-ubiquitin ligase. Both mammalian and Drosophila parkin is capable of ubiquitylating mitofusin under these circumstances, causing degradation via the proteasome (Gegg et al. 
2010; Poole et al. 2010; Tanaka et al. 2010; Ziviani et al. 2010; Glauser et al. 2011; Lee et al. 2011; Rakovic et al. 2011). Mitofusins are large GTPases that sit on the mitochondrial surface and promote mitochondrial fusion. This is a regulated, dynamic process that allows for the redistribution of mtDNA and other components. Fused mitochondria are not suitable for degradation via mitophagy, thus the concept is that limiting fission allows for mitophagy.

Most of the above studies considered mitofusins as a candidate substrate, but the same proteins were also identified as being ubiquitylated and turned over by parkin in an unbiased proteomics screen (Chan et al. 2011). However, and perhaps surprisingly, many other mitochondrial proteins were also degraded under the same circumstances. One interpretation of these data is that parkin is somewhat nonspecific as an enzyme and that once activated may generally be able to scaffold substrates and the E2 ubiquitin carrier in a concentration-dependent manner.

Subsequently, several groups showed that PINK1 was required for the process of recruitment of parkin under these conditions (Geisler et al. 2010; Kawajiri et al. 2010; Matsuda et al. 2010; Narendra et al. 2010; Vives-Bauza et al. 2010; Glauser et al. 2011; Rakovic et al. 2011). The recruitment of parkin requires kinase activity of PINK1 and for PINK1 to be present on the outer mitochondrial membrane. It has been suggested that the mechanism involves stabilization of PINK1 due to inhibition of cleavage by a membrane potential-sensitive protease, probably PARL (Jin et al. 2010; Deas et al. 2011; Meissner et al. 2011).

Importantly, disease-associated mutations in PINK1 all block the ability to support parkin recruitment. Similarly, mutations in parkin either are not recruited to mitochondria by PINK1 or are recruited and do not support mitophagy. This suggests that the process of recruitment of parkin in a PINK1-dependent manner may be central to inherited parkinsonism.

Furthermore, these data would also suggest that PINK1 and parkin are in the same biochemical pathway, as well as having a genetic relationship. The question, however, remains as to whether these two sets of data can be fully reconciled. Recruitment of parkin in mammalian cells under depolarizing conditions does not occur to a measureable extent in the absence of PINK1. Therefore, mitochondrial recruitment of parkin would not logically be connected to the genetic results in Drosophila.

Part of the answer may be that there is a function of parkin that is not strictly dependent on recruitment. One possible answer comes from studies examining substrates of parkin that are present in the cytoplasm and nucleus. Parkin has been proposed to regulate the turnover of the zinc finger protein ZNF746 (also referred to as PARIS, for parkin interacting substrate) via the proteasome (Shin et al. 2011). If parkin is absent, mutated, or modified by free radicals, the ZNF746 accumulates. Importantly, as a zinc finger protein, PARIS/ZNF746 binds to DNA and controls transcription of $\mathrm{PGC} 1 \alpha$, itself a transcription coactivator for several nuclear genes that control mitochondrial and oxidative metabolism (Zheng et al. 2010). Parkin may also have an impact on lipid metabolism pathways via turnover of CD36 (Kim et al. 2011), which is present in vesicular structures (Steinbusch et al. 2011), showing how it might affect multiple pathways.

Therefore, it is possible that parkin has two distinct sets of functions, one requiring recruitment to the outer mitochondrial membrane, which is dependent on PINK1, and one in which cytosolic/nuclear localization is important, which may or may not be PINK1 dependent. If correct, this predicts that parkin overexpression can rescue PINK1 by overcoming the lack of turnover of mitochondrial proteins, perhaps via up-regulation of mitochondrial biogenesis. This would resolve the apparent contradictions in some of these models and may explain why the rescue of PINK1-deficiency phenotypes by parkin in flies is only a partial effect. This may also be related to observations of changes in PGC1 $\alpha$-responsive genes in fibroblasts from parkin mutation carriers (Pacelli et al. 2011). Finally, if it is correct that there are many functional locations of parkin, we might surmise that the apparent lack of specificity of the protein may have evolved from a need to coordinate 
M.R. Cookson

several pathways; certainly mitochondrial biogenesis and turnover will be regulated by some of the same pathways.

However, there are still some mysteries concerning the PINK1/parkin pathway. One difficulty is that overexpression and knockout of parkin do not always give the expected opposite results. For example, older data showed that parkin overexpression would limit toxic effects of $\alpha$-synuclein in vitro (Petrucelli et al. 2002) and in vivo (Lo Bianco et al. 2002), but knockout of parkin does not enhance toxic effects of $\alpha$-synuclein in a transgenic animal model (von Coelln et al. 2006). Similarly, although turnover of mitofusins by parkin is associated with fragmentation of mitochondria before mitophagy (Yu et al. 2011), loss of parkin or PINK1 is also associated with shorter mitochondria (Exner et al. 2007; Lutz et al. 2009; Sandebring et al. 2009; Thomas et al. 2011). Some of these contradictions may come about because of the different context of acutely activated parkin (e.g., by CCCP) versus long-term knockdown of the same gene in the context of altered regulation of other processes. For example, we have shown that in PINK1-deficient cells, there is activation of the phosphatase calcineurin, which influences the fusion protein Drp1 leading to fragmentation (Sandebring et al. 2009). Nonetheless, it is a concern that there is not a simple relationship between increased and decreased parkin function in all cases.

There are also some reasonable questions as to whether the mitophagy function of parkin is important in neurons. Specifically, it has been claimed that the relocalization of parkin to mitochondria does not occur in cortical or stria$\mathrm{tal} /$ midbrain cultures because of differences in bioenergetics compared with cell lines (Yu et al. 2011). The real question is, What happens in the brain? Experiments using knockout animals suggest that parkin is not recruited to complex $\mathrm{I}$-deficient mitochondria and is not required for turnover of what are presumably energetically compromised organelles (Sterky et al. 2011). Therefore, why parkin recruitment works well in some contexts and not in others still needs to be resolved, with particular attention being paid to the timing of events.
This leads us back to a fairly fundamental question regarding the Drosophila models. One of the reasons that the experiments in flies were so reproducible was because the phenotypes were very robust and clearly related to mitochondrial function. Yet, in humans, the phenotype is less obviously related to multisystem mitochondrial problems, because a relatively pure, mild parkinsonism is much more subtle than classic mitochondrial disorders (Distelmaier et al. 2009). The mouse knockout models also only showed subtle mitochondrial phenotypes, perhaps suggesting that deficiency in the same gene in different species results in a different degree of effect. It might further be possible that the PINK1/parkin pathway is subtly different in Drosophila. For example, it could be that regulation of PINK1/parkin differs and might be constitutive in Drosophila but more dependent on membrane potential in vertebrates. In addition, we might consider that each organism may prioritize mitochondrial function in different ways. In the short-lived flies, perhaps more energy production is needed for spermatogenesis and flight compared with humans, where one might hope the brain would account for a bigger fraction of glucose utilization.

The next major challenge will be to resolve some of these abstract issues regarding the PINK1/parkin pathway so that we can better understand the models that we have. Relatively little attention has been given to how these processes affect mature dopamine neurons, although some excellent tools have been developed including conditional knockouts of parkin in the mature mouse brain achieved using virally delivered recombinases (Shin et al. 2011).

\section{WHAT DOES DJ-1 ACTUALLY DO?}

All known DJ-1 homologs are relatively small proteins (22 $\mathrm{kDa}$ in humans) that form dimers in solution and in crystal structures. There are specific residues that are extremely highly conserved, including the cysteine residue (C106 in humans) in a predicted nucleophile elbow that appears to respond to oxidative stress by forming a sulfinic acid (Honbou et al. 2003; Huai 
et al. 2003; Lee et al. 2003; Tao and Tong 2003; Wilson et al. 2003).

Several experiments in cell models (CanetAviles et al. 2004; Takahashi-Niki et al. 2004), Drosophila (Meulener et al. 2006), and in a rat model of stroke (Aleyasin et al. 2007) have all shown that C106 is essential for the activity of DJ-1, because replacement with other amino acids blocks neuroprotection. There is a remaining question regarding whether the sulhydryl group on the cysteine or the sulfinic acid on the modified side chain is critical, because substitution for a charged aspartate residue is not neuroprotective (Meulener et al. 2006). Our own work has shown that modulation of the ability of the cysteine to sustain a sulfinic acid, by modulating a nearby glutamate residue without changing C106 itself, affects the ability of DJ-1 to protect against mitochondrial damage in cells (Blackinton et al. 2009). Therefore, available evidence would support the idea that the modification of DJ-1 is important for function.

The question then becomes, What is the function of DJ-1? The above data reinforce the idea that oxidative stress is mechanistically important somehow, but the molecular details are vague. One possibility is that DJ-1 has a rather direct antioxidant-scavenging role, but this is probably not sufficient to explain the role of DJ-1 in disease for two reasons. First, cells have many other antioxidants that are efficient and are present at relatively high concentrations. For example, glutathione has three free sulhydryl groups and is present at up to $5 \mathrm{~mm}$ in the liver, many times the concentrations that proteins reach. Therefore, unless DJ-1 has a very specific antioxidant capacity, it is not likely to influence overall reactive oxygen species (ROS) levels to any significant extent. In addition, when the rate constant for reaction of hydrogen peroxide with DJ-1 was measured, this was far less than for known enzymes such as peroxiredoxins (Andres-Mateos et al. 2007), although C106 was again identified as the critical residue.

If DJ-1 is responsive to oxidative stress but does not have enough substantive enzyme activity to decrease ROS within a cell directly, then it is likely to have another function that is evolutionarily conserved. For example, based on amino acid similarity to other members of the DJ-1 superfamily, it has been suggested that DJ-1 may be a chaperone (Shendelman et al. 2004; Zhou et al. 2006) or a protease (Olzmann et al. 2004; Chen et al. 2010), although the structural basis of these activities is unclear. Additionally, several protein interactors have been proposed, but these are generally not conserved across evolution, and thus it is not clear if they represent a general aspect of DJ-1 function.

Overall, there is no clear connection between DJ-1 function and its ability to protect cells against mitochondrial damage other than an ability to suppress oxidative stress. These are likely related given that depolarized mitochondria can leak electrons to cause ROS. There is evidence that hydrogen peroxide, formed by reaction of electrons in an aqueous environment, can act as a neuromodulator in the dopaminergic system, with the net effect of slowing dopamine release (Rice 2011).

In this context, it is interesting that substantia nigra neurons, which are relatively affected in parkinsonism, have different mitochondrial properties compared with other types of cells (Guzman et al. 2010). Importantly, DJ-1 will suppress this excess oxidative stress production. Therefore, it is possible that within the mammalian system, the effects of DJ-1 are relatively subtle because, rather than dealing with bulk radical formation in all tissues, the protein has evolved to be important only in some contexts, such as balancing excess $\mathrm{H}_{2} \mathrm{O}_{2}$ signaling in some cell types. This may be supported by the observations of altered dopamine release in DJ-1-deficient animals (Chen et al. 2005; Goldberg et al. 2005; Pisani et al. 2006; Ishikawa et al. 2009; Martella et al. 2011).

It is also worth considering the relationships between DJ-1 and the PINK1/parkin pathway in the context of biochemical functions. Phenomenologically, all three proteins exert an effect on mitophagy, because DJ-1 deficiency increases markers of autophagy (Gonzalez-Polo et al. 2009; Krebiehl et al. 2010; Thomas et al. 2011). In our own experiments, there is an accumulation of LC3, a marker of autophagy, near mitochondria in DJ-1-deficient cells, and this can be blocked by antioxidants (Thomas et al. 2011). 
M.R. Cookson

This would indicate that such effects are probably downstream from the primary action of DJ1 , which contrasts to the more primary role of PINK1 and parkin in signaling and triggering the removal of mitochondria. This is perhaps one way in which the three proteins might be in somewhat parallel pathways, leading to an increased rate of mitochondrial turnover due to oxidative damage (DJ-1 deficiency) or failing to clear defective mitochondria (PINK1/parkin deficiency) even if there are no close biochemical links between the three.

\section{CONCLUDING REMARKS}

The fairly substantial body of work in the literature on PINK1, parkin, and DJ-1 has highlighted several critical pathways that are probably involved in recessive parkinsonism. This is drawn from a number of experimental systems, and understanding what each of them tells us involves some knowledge the evolutionary relationships between the organisms studied and how the genes function in each. What is clear is that at least some functions are conserved, but there are likely to be subtleties in usage that have driven the relative phenotypes in each model system.

What still needs to be resolved are the finegrained details of mechanisms by which PINK1/ parkin and DJ-1 function. In particular, there are unresolved questions regarding the ability of parkin to rescue PINK1 deficiency, where the data in flies and in cell culture need to be reconciled. There are also significant gaps in our knowledge regarding which of these functions can be shown to be active in the mature mammalian brain, particularly in dopaminergic neurons. Finally, whereas the enzymatic functions of PINK1 and parkin are known, the precise biochemical function of DJ-1 is still somewhat mysterious, and this might be important in understanding which functions of the overall pathway lead to dopamine cell loss, with the important caveat that DJ-1 appears to be in a parallel pathway and therefore might partially be a phenocopy of PINK1/parkin deficiency.

As a final thought, it is of fairly substantial concern that little of this knowledge has impacted the people who have any of these diseases. In part, this simply justifies knowing more regarding the biology so that we can develop appropriately targeted approaches, because biological processes as broad as oxidative stress or mitochondrial function have not yet yielded much in the way of therapeutics. But in addition, this reinforces the notion that although human genetics has told us a great deal, we still need to find ways to apply it back to humans, and this constitutes the biggest challenge we face.

\section{ACKNOWLEDGMENTS}

This research is supported by the Intramural Research Program of the NIH, National Institute on Aging.

\section{REFERENCES}

Aleyasin H, Rousseaux MW, Phillips M, Kim RH, Bland RJ, Callaghan S, Slack RS, During MJ, Mak TW, Park DS. 2007. The Parkinson's disease gene DJ-1 is also a key regulator of stroke-induced damage. Proc Natl Acad Sci 104: $18748-18753$.

Andres-Mateos E, Perier C, Zhang L, Blanchard-Fillion B, Greco TM, Thomas B, Ko HS, Sasaki M, Ischiropoulos H, Przedborski S, et al. 2007. DJ-1 gene deletion reveals that DJ-1 is an atypical peroxiredoxin-like peroxidase. Proc Natl Acad Sci 104: 14807-14812.

Bandyopadhyay S, Cookson MR. 2004. Evolutionary and functional relationships within the DJ1 superfamily. BMC Evol Biol 4: 6.

Blackinton J, Lakshminarasimhan M, Thomas KJ, Ahmad R, Greggio E, Raza AS, Cookson MR, Wilson MA. 2009. Formation of a stabilized cysteine sulfinic acid is critical for the mitochondrial function of the parkinsonism protein DJ-1. J Biol Chem 284: 6476-6485.

Bonifati V, Rizzu P, van Baren MJ, Schaap O, Breedveld GJ, Krieger E, Dekker MC, Squitieri F, Ibanez P, Joosse M, et al. 2003. Mutations in the DJ-1 gene associated with autosomal recessive early-onset parkinsonism. Science 299: 256-259.

Canet-Aviles RM, Wilson MA, Miller DW, Ahmad R, McLendon C, Bandyopadhyay S, Baptista MJ, Ringe D, Petsko GA, Cookson MR. 2004. The Parkinson's disease protein DJ-1 is neuroprotective due to cysteine-sulfinic acid-driven mitochondrial localization. Proc Natl Acad Sci 101: 9103-9108.

Chan NC, Salazar AM, Pham AH, Sweredoski MJ, Kolawa NJ, Graham RL, Hess S, Chan DC. 2011. Broad activation of the ubiquitin-proteasome system by Parkin is critical for mitophagy. Hum Mol Genet 20: 1726-1737.

Chen L, Cagniard B, Mathews T, Jones S, Koh HC, Ding Y, Carvey PM, Ling Z, Kang UJ, Zhuang X. 2005. Age-dependent motor deficits and dopaminergic dysfunction in DJ-1 null mice. J Biol Chem 280: $21418-$ 21426. 
PINK1, Parkin, and DJ-1

Chen J, Li L, Chin LS. 2010. Parkinson disease protein DJ-1 converts from a zymogen to a protease by carboxyl-terminal cleavage. Hum Mol Genet 19: 2395-2408.

Clark IE, Dodson MW, Jiang C, Cao JH, Huh JR, Seol JH, Yoo SJ, Hay BA, Guo M. 2006. Drosophila pink1 is required for mitochondrial function and interacts genetically with parkin. Nature 441: 1162-1166.

Cookson MR, Lockhart PJ, McLendon C, O'Farrell C, Schlossmacher M, Farrer MJ. 2003. RING finger 1 mutations in Parkin produce altered localization of the protein. Hum Mol Genet 12: 2957-2965.

Darios F, Corti O, Lucking CB, Hampe C, Muriel MP, Abbas N, Gu WJ, Hirsch EC, Rooney T, Ruberg M, et al. 2003. Parkin prevents mitochondrial swelling and cytochrome $c$ release in mitochondria-dependent cell death. Hum Mol Genet 12: 517-526.

Deas E, Plun-Favreau H, Gandhi S, Desmond H, Kjaer S, Loh SH, Renton AE, Harvey RJ, Whitworth AJ, Martins LM, et al. 2011. PINK1 cleavage at position A103 by the mitochondrial protease PARL. Hum Mol Genet 20: $867-$ 879.

Distelmaier F, Koopman WJ, van den Heuvel LP, Rodenburg RJ, Mayatepek E, Willems PH, Smeitink JA. 2009. Mitochondrial complex I deficiency: From organelle dysfunction to clinical disease. Brain 132: 833-842.

Exner N, Treske B, Paquet D, Holmstrom K, Schiesling C, Gispert S, Carballo-Carbajal I, Berg D, Hoepken HH, Gasser T, et al. 2007. Loss-of-function of human PINK1 results in mitochondrial pathology and can be rescued by parkin. J Neurosci 27: 12413-12418.

Gegg ME, Cooper JM, Chau KY, Rojo M, Schapira AH, Taanman JW. 2010. Mitofusin 1 and mitofusin 2 are ubiquitinated in a PINK1/parkin-dependent manner upon induction of mitophagy. Hum Mol Genet 19: 4861-4870.

Geisler S, Holmstrom KM, Treis A, Skujat D, Weber SS, Fiesel FC, Kahle PJ, Springer W. 2010. The PINK1/Parkin-mediated mitophagy is compromised by $\mathrm{PD}$-associated mutations. Autophagy 6: 871-878.

Glauser L, Sonnay S, Stafa K, Moore DJ. 2011. Parkin promotes the ubiquitination and degradation of the mitochondrial fusion factor mitofusin 1. J Neurochem 118: 636-645.

Goldberg MS, Pisani A, Haburcak M, Vortherms TA, Kitada T, Costa C, Tong Y, Martella G, Tscherter A, Martins A, et al. 2005. Nigrostriatal dopaminergic deficits and hypokinesia caused by inactivation of the familial Parkinsonism-linked gene DJ-1. Neuron 45: 489-496.

Gonzalez-Polo R, Niso-Santano M, Moran JM, Ortiz-Ortiz MA, Bravo-San Pedro JM, Soler G, Fuentes JM. 2009. Silencing DJ-1 reveals its contribution in paraquat-induced autophagy. J Neurochem 109: 889-898.

Greene JC, Whitworth AJ, Kuo I, Andrews LA, Feany MB, Pallanck LJ. 2003. Mitochondrial pathology and apoptotic muscle degeneration in Drosophila parkin mutants. Proc Natl Acad Sci 100: 4078-4083.

Guzman JN, Sanchez-Padilla J, Wokosin D, Kondapalli J, Ilijic E, Schumacker PT, Surmeier DJ. 2010. Oxidant stress evoked by pacemaking in dopaminergic neurons is attenuated by DJ-1. Nature 468: 696-700.

Hampe C, Ardila-Osorio H, Fournier M, Brice A, Corti O. 2006. Biochemical analysis of Parkinson's disease-caus- ing variants of Parkin, an E3 ubiquitin-protein ligase with monoubiquitylation capacity. Hum Mol Genet 15: 20592075.

Hao LY, Giasson BI, Bonini NM. 2010. DJ-1 is critical for mitochondrial function and rescues PINK1 loss of function. Proc Natl Acad Sci 107: 9747-9752.

Hardy J, Lees AJ. 2005. Parkinson's disease: A broken nosology. Mov Disord 20: S2-S4.

Hardy J, Lewis P, Revesz T, Lees A, Paisan-Ruiz C. 2009. The genetics of Parkinson's syndromes: A critical review. Curr Opin Genet Dev 19: 254-265.

Honbou K, Suzuki NN, Horiuchi M, Niki T, Taira T, Ariga H, Inagaki F. 2003. The crystal structure of DJ-1, a protein related to male fertility and Parkinson's disease. J Bio Chem 278: 31380-31384.

Huai Q, Sun Y, Wang H, Chin LS, Li L, Robinson H, Ke H. 2003. Crystal structure of DJ-1/RS and implication on familial Parkinson's disease. FEBS Lett 549: 171-175.

Ishikawa A, Tsuji S. 1996. Clinical analysis of 17 patients in 12 Japanese families with autosomal-recessive type juvenile parkinsonism. Neurology 47: 160-166.

Ishikawa S, Taira T, Niki T, Takahashi-Niki K, Maita C, Maita $\mathrm{H}$, Ariga H, Iguchi-Ariga SM. 2009. Oxidative status of DJ-1-dependent activation of dopamine synthesis through interaction of tyrosine hydroxylase and 4-dihydroxy-L-phenylalanine (L-DOPA) decarboxylase with DJ1. J Biol Chem 284: 28832-28844.

Jin SM, Lazarou M, Wang C, Kane LA, Narendra DP, Youle RJ. 2010. Mitochondrial membrane potential regulates PINK1 import and proteolytic destabilization by PARL. J Cell Biol 191: 933-942.

Kawajiri S, Saiki S, Sato S, Sato F, Hatano T, Eguchi H, Hattori N. 2010. PINK1 is recruited to mitochondria with parkin and associates with LC3 in mitophagy. FEBS Lett 584: 1073-1079.

Kim KY, Stevens MV, Akter MH, Rusk SE, Huang RJ, Cohen A, Noguchi A, Springer D, Bocharov AV, Eggerman TL, et al. 2011. Parkin is a lipid-responsive regulator of fat uptake in mice and mutant human cells. J Clin Invest 121: 3701-3712.

Kitada T, Asakawa S, Hattori N, Matsumine H, Yamamura Y, Minoshima S, Yokochi M, Mizuno Y, Shimizu N. 1998. Mutations in the parkin gene cause autosomal recessive juvenile parkinsonism. Nature 392: 605-608.

Kitada T, Tong Y, Gautier CA, Shen J. 2009. Absence of nigral degeneration in aged parkin/DJ-1/PINK1 triple knockout mice. J Neurochem 111: 696-702.

Klein C, Schneider SA, Lang AE. 2009. Hereditary parkinsonism: Parkinson disease look-alikes-An algorithm for clinicians to "PARK" genes and beyond. Mov Disord 24: 2042-2058.

Krebiehl G, Ruckerbauer S, Burbulla LF, Kieper N, Maurer B, Waak J, Wolburg H, Gizatullina Z, Gellerich FN, Woitalla D, et al. 2010. Reduced basal autophagy and impaired mitochondrial dynamics due to loss of Parkinson's disease-associated protein DJ-1. PLoS ONE 5: e9367.

Kuroda Y, Mitsui T, Kunishige M, Shono M, Akaike M, Azuma H, Matsumoto T. 2006. Parkin enhances mitochondrial biogenesis in proliferating cells. Hum $\mathrm{Mol} \mathrm{Ge}$ net 15: $883-895$. 
M.R. Cookson

Lavara-Culebras E, Paricio N. 2007. Drosophila DJ-1 mutants are sensitive to oxidative stress and show reduced lifespan and motor deficits. Gene 400: 158-165.

Lee SJ, Kim SJ, Kim IK, Ko J, Jeong CS, Kim GH, Park C, Kang SO, Suh PG, Lee HS, et al. 2003. Crystal structures of human DJ-1 and Escherichia coli Hsp31, which share an evolutionarily conserved domain. J Biol Chem 278: 44552-44559.

Lee Y, Lee HY, Hanna RA, Gustafsson AB. 2011. Mitochondrial autophagy by Bnip3 involves Drp1-mediated mitochondrial fission and recruitment of Parkin in cardiac myocytes. Am J Physiol Heart Circ Physiol 301: H1924H1931.

Lo Bianco C, Ridet JL, Schneider BL, Deglon N, Aebischer P. 2002. $\alpha$-Synucleinopathy and selective dopaminergic neuron loss in a rat lentiviral-based model of Parkinson's disease. Proc Natl Acad Sci 99: 10813-10818.

Lucas JI, Marin I. 2007. A new evolutionary paradigm for the Parkinson disease gene DJ-1. Mol Biol Evol 24: 551561.

Lutz AK, Exner N, Fett ME, Schlehe JS, Kloos K, Lammermann K, Brunner B, Kurz-Drexler A, Vogel F, Reichert AS, et al. 2009. Loss of parkin or PINK1 function increases Drp1-dependent mitochondrial fragmentation. J Biol Chem 284: 22938-22951.

Martella G, Madeo G, Schirinzi T, Tassone A, Sciamanna G Spadoni F, Stefani A, Shen J, Pisani A, Bonsi P. 2011. Altered profile and D2-dopamine receptor modulation of high voltage-activated calcium current in striatal medium spiny neurons from animal models of Parkinson's disease. Neuroscience 177: 240-251.

Matsuda N, Sato S, Shiba K, Okatsu K, Saisho K, Gautier CA, Sou YS, Saiki S, Kawajiri S, Sato F, et al. 2010. PINK1 stabilized by mitochondrial depolarization recruits Parkin to damaged mitochondria and activates latent Parkin for mitophagy. J Cell Biol 189: 211-221.

Meissner C, Lorenz H, Weihofen A, Selkoe DJ, Lemberg MK. 2011. The mitochondrial intramembrane protease PARL cleaves human Pink1 to regulate Pink1 trafficking. J Neurochem 117: 856-867.

Menzies FM, Yenisetti SC, Min KT. 2005. Roles of Drosophila DJ-1 in survival of dopaminergic neurons and oxidative stress. Curr Biol 15: 1578-1582.

Meulener M, Whitworth AJ, Armstrong-Gold CE, Rizzu P, Heutink P, Wes PD, Pallanck LJ, Bonini NM. 2005. Drosophila DJ-1 mutants are selectively sensitive to environmental toxins associated with Parkinson's disease. Curr Biol 15: 1572-1577.

Meulener MC, Xu K, Thomson L, Ischiropoulos H, Bonini NM. 2006. Mutational analysis of DJ-1 in Drosophila implicates functional inactivation by oxidative damage and aging. Proc Natl Acad Sci 103: 12517-12522.

Narendra D, Tanaka A, Suen DF, Youle RJ. 2008. Parkin is recruited selectively to impaired mitochondria and promotes their autophagy. J Cell Biol 183: 795-803.

Narendra DP, Jin SM, Tanaka A, Suen DF, Gautier CA, Shen J, Cookson MR, Youle RJ. 2010. PINK1 is selectively stabilized on impaired mitochondria to activate Parkin. PLoS Biol 8: e1000298.

Nuytemans K, Theuns J, Cruts M, Van Broeckhoven C. 2010. Genetic etiology of Parkinson disease associated with mutations in the SNCA, PARK2, PINK1, PARK7, and LRRK2 genes: A mutation update. Hum Mutat 31: 763-780.

Olzmann JA, Brown K, Wilkinson KD, Rees HD, Huai Q, Ke H, Levey AI, Li L, Chin LS. 2004. Familial Parkinson's disease-associated L166P mutation disrupts DJ-1 protein folding and function. J Biol Chem 279: 8506-8515.

Pacelli C, De Rasmo D, Signorile A, Grattagliano I, di Tullio G, D’Orazio A, Nico B, Comi GP, Ronchi D, Ferranini E, et al. 2011. Mitochondrial defect and PGC-1 $\alpha$ dysfunction in parkin-associated familial Parkinson's disease. Biochim Biophys Acta 1812: 1041-1053.

Palacino JJ, Sagi D, Goldberg MS, Krauss S, Motz C, Wacker M, Klose J, Shen J. 2004. Mitochondrial dysfunction and oxidative damage in parkin-deficient mice. J Biol Chem 279: 18614-18622.

Park J, Kim SY, Cha GH, Lee SB, Kim S, Chung J. 2005. Drosophila DJ-1 mutants show oxidative stress-sensitive locomotive dysfunction. Gene 361: 133-139.

Park J, Lee SB, Lee S, Kim Y, Song S, Kim S, Bae E, Kim J, Shong M, Kim JM, et al. 2006. Mitochondrial dysfunction in Drosophila PINK1 mutants is complemented by parkin. Nature 441: 1157-1161.

Pesah Y, Pham T, Burgess H, Middlebrooks B, Verstreken P, Zhou Y, Harding M, Bellen H, Mardon G. 2004. Drosophila parkin mutants have decreased mass and cell size and increased sensitivity to oxygen radical stress. Development 131: 2183-2194.

Petrucelli L, O’Farrell C, Lockhart PJ, Baptista M, Kehoe K, Vink L, Choi P, Wolozin B, Farrer M, Hardy J, et al. 2002. Parkin protects against the toxicity associated with mutant $\alpha$-synuclein: Proteasome dysfunction selectively affects catecholaminergic neurons. Neuron 36: 1007-1019.

Pisani A, Martella G, Tscherter A, Costa C, Mercuri NB, Bernardi G, Shen J, Calabresi P. 2006. Enhanced sensitivity of DJ-1-deficient dopaminergic neurons to energy metabolism impairment: role of $\mathrm{Na}^{+} / \mathrm{K}^{+}$ATPase. Neurobiol Dis 23: 54-60.

Poole AC, Thomas RE, Yu S, Vincow ES, Pallanck L. 2010. The mitochondrial fusion-promoting factor mitofusin is a substrate of the PINK1/parkin pathway. PLoS ONE 5: e10054.

Rakovic A, Grunewald A, Kottwitz J, Bruggemann N, Pramstaller PP, Lohmann K, Klein C. 2011. Mutations in PINK1 and Parkin impair ubiquitination of Mitofusins in human fibroblasts. PLoS ONE 6: e16746.

Rice ME. 2011. $\mathrm{H}_{2} \mathrm{O}_{2}$ : A dynamic neuromodulator. Neuroscientist 17: 389-406.

Samaranch L, Lorenzo-Betancor O, Arbelo JM, Ferrer I, Lorenzo E, Irigoyen J, Pastor MA, Marrero C, Isla C, Herrera-Henriquez J, et al. 2010. PINK1-linked parkinsonism is associated with Lewy body pathology. Brain 133: $1128-1142$.

Sandebring A, Thomas KJ, Beilina A, van der Brug M, Cleland MM, Ahmad R, Miller DW, Zambrano I, Cowburn RF, Behbahani H, et al. 2009. Mitochondrial alterations in PINK1 deficient cells are influenced by calcineurindependent dephosphorylation of dynamin-related protein 1. PLoS ONE 4: e5701.

Sasaki S, Shirata A, Yamane K, Iwata M. 2004. Parkin-positive autosomal recessive juvenile Parkinsonism with $\alpha$ synuclein-positive inclusions. Neurology 63: 678-682. 
PINK1, Parkin, and DJ-1

Shendelman S, Jonason A, Martinat C, Leete T, Abeliovich A. 2004. DJ-1 is a redox-dependent molecular chaperone that inhibits $\alpha$-synuclein aggregate formation. PLoS Biol 2: e362.

Shin JH, Ko HS, Kang H, Lee Y, Lee YI, Pletinkova O, Troconso JC, Dawson VL, Dawson TM. 2011. PARIS (ZNF746) repression of PGC- $1 \alpha$ contributes to neurodegeneration in Parkinson's disease. Cell 144: 689-702.

Sriram SR, Li X, Ko HS, Chung KK, Wong E, Lim KL, Dawson VL, Dawson TM. 2005. Familial-associated mutations differentially disrupt the solubility, localization, binding and ubiquitination properties of parkin. Hum Mol Genet 14: 2571-2586.

Steinbusch LK, Schwenk RW, Ouwens DM, Diamant M, Glatz JF, Luiken JJ. 2011. Subcellular trafficking of the substrate transporters GLUT4 and CD36 in cardiomyocytes. Cell Mol Life Sci 68: 2525-2538.

Sterky FH, Lee S, Wibom R, Olson L, Larsson NG. 2011. Impaired mitochondrial transport and Parkin-independent degeneration of respiratory chain-deficient dopamine neurons in vivo. Proc Natl Acad Sci 108: 12937 12942.

Suen DF, Narendra DP, Tanaka A, Manfredi G, Youle RJ. 2010. Parkin overexpression selects against a deleterious mtDNA mutation in heteroplasmic cybrid cells. Proc Natl Acad Sci 107: 11835-11840.

Surmeier DJ, Guzman JN, Sanchez-Padilla J, Goldberg JA. 2011. The origins of oxidant stress in Parkinson's disease and therapeutic strategies. Antioxid Redox Signal 14: 1289-1301.

Takahashi-Niki K, Niki T, Taira T, Iguchi-Ariga SM, Ariga H. 2004. Reduced anti-oxidative stress activities of DJ-1 mutants found in Parkinson's disease patients. Biochem Biophys Res Commun 320: 389-397.

Tanaka A, Cleland MM, Xu S, Narendra DP, Suen DF, Karbowski M, Youle RJ. 2010. Proteasome and p97 mediate mitophagy and degradation of mitofusins induced by Parkin. J Cell Biol 191: 1367-1380.

Tao X, Tong L. 2003. Crystal structure of human DJ-1, a protein associated with early onset Parkinson's disease. J Biol Chem 278: 31372-31379.

Thomas KJ, McCoy MK, Blackinton J, Beilina A, van der Brug M, Sandebring A, Miller D, Maric D, Cedazo-Minguez A, Cookson MR, et al. 2011. DJ-1 acts in parallel to the PINK1/parkin pathway to control mitochondrial function and autophagy. Hum Mol Genet 20: 40-50.
Valente EM, Abou-Sleiman PM, Caputo V, Muqit MM, Harvey K, Gispert S, Ali Z, Del Turco D, Bentivoglio AR, Healy DG, et al. 2004. Hereditary early-onset Parkinson's disease caused by mutations in PINK1. Science 304: $1158-1160$.

Vives-Bauza C, Zhou C, Huang Y, Cui M, de Vries RL, Kim J, May J, Tocilescu MA, Liu W, Ko HS, et al. 2010. PINK1dependent recruitment of Parkin to mitochondria in mitophagy. Proc Natl Acad Sci 107: 378-383.

von Coelln R, Thomas B, Andrabi SA, Lim KL, Savitt JM, Saffary R, Stirling W, Bruno K, Hess EJ, Lee MK, et al. 2006. Inclusion body formation and neurodegeneration are parkin independent in a mouse model of $\alpha$-synucleinopathy. J Neurosci 26: 3685-3696.

Wilson MA, Collins JL, Hod Y, Ringe D, Petsko GA. 2003. The 1.1-A resolution crystal structure of DJ-1, the protein mutated in autosomal recessive early onset Parkinson's disease. Proc Natl Acad Sci 100: 9256-9261.

Yang Y, Gehrke S, Haque ME, Imai Y, Kosek J, Yang L, Beal MF, Nishimura I, Wakamatsu K, Ito S, et al. 2005. Inactivation of Drosophila DJ-1 leads to impairments of oxidative stress response and phosphatidylinositol 3-kinase/Akt signaling. Proc Natl Acad Sci 102: 1367013675.

Yao Z, Wood NW. 2009. Cell death pathways in Parkinson's disease: Role of mitochondria. Antioxid Redox Signal 11: 2135-2149.

Yokochi M. 1997. Familial juvenile parkinsonism. Eur Neurol 38: 29-33.

Yu W, Sun Y, Guo S, Lu B. 2011. The PINK1/Parkin pathway regulates mitochondrial dynamics and function in mammalian hippocampal and dopaminergic neurons. Hum Mol Genet 20: 3227-3240.

Zheng B, Liao Z, Locascio JJ, Lesniak KA, Roderick SS, Watt ML, Eklund AC, Zhang-James Y, Kim PD, Hauser MA, et al. 2010. PGC-1 $\alpha$, a potential therapeutic target for early intervention in Parkinson's disease. Sci Transl Med 2: 52 ra73.

Zhou W, Zhu M, Wilson MA, Petsko GA, Fink AL. 2006. The oxidation state of DJ-1 regulates its chaperone activity toward $\alpha$-synuclein. J Mol Biol 356: 1036-1048.

Ziviani E, Tao RN, Whitworth AJ. 2010. Drosophila parkin requires PINK1 for mitochondrial translocation and ubiquitinates mitofusin. Proc Natl Acad Sci 107: 5018 5023. 


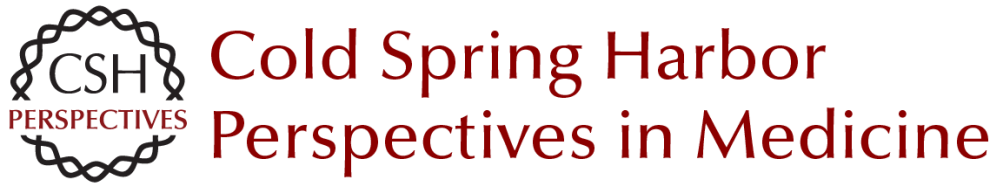

\title{
Parkinsonism Due to Mutations in PINK1, Parkin, and DJ-1 and Oxidative Stress and Mitochondrial Pathways
}

\author{
Mark R. Cookson
}

Cold Spring Harb Perspect Med 2012; doi: 10.1101/cshperspect.a009415 originally published online August 22, 2012

\section{Subject Collection Parkinson's Disease}

Functional Neuroanatomy of the Basal Ganglia José L. Lanciego, Natasha Luquin and José A. Obeso

Animal Models of Parkinson's Disease: Vertebrate Genetics Yunjong Lee, Valina L. Dawson and Ted M. Dawson

Innate Inflammation in Parkinson's Disease V. Hugh Perry

Parkinson's Disease and Parkinsonism:

Neuropathology Dennis W. Dickson

Physiological Phenotype and Vulnerability in Parkinson's Disease

D. James Surmeier, Jaime N. Guzman, Javier Sanchez, et al.

Clinical Approach to Parkinson's Disease:

Features, Diagnosis, and Principles of

Management João Massano and Kailash P. Bhatia

The Role of Autophagy in Parkinson's Disease Melinda A. Lynch-Day, Kai Mao, Ke Wang, et al.

Disruption of Protein Quality Control in

Parkinson's Disease

Casey Cook, Caroline Stetler and Leonard Petrucelli

\section{Drosophila as a Model to Study Mitochondrial Dysfunction in Parkinson's Disease Ming Guo}

Parkinsonism Due to Mutations in PINK1, Parkin, and DJ-1 and Oxidative Stress and Mitochondrial Pathways Mark R. Cookson

Programmed Cell Death in Parkinson's Disease Katerina Venderova and David S. Park

Genomics and Bioinformatics of Parkinson's Disease

Sonja W. Scholz, Tim Mhyre, Habtom Ressom, et al.

Motor Control Abnormalities in Parkinson's

Disease

Pietro Mazzoni, Britne Shabbott and Juan Camilo Cortés

Parkinson's Disease: Gene Therapies Philippe G. Coune, Bernard L. Schneider and Patrick Aebischer

Functional Neuroimaging in Parkinson's Disease Martin Niethammer, Andrew Feigin and David Eidelberg

Leucine-Rich Repeat Kinase 2 for Beginners: Six Key Questions Lauren R. Kett and William T. Dauer

For additional articles in this collection, see http://perspectivesinmedicine.cshlp.org/cgi/collection/ 